\title{
Monitoring, Scaffolding, Intervening, and Overriding: Adult Children's Perspectives on Supporting Older Parents
}

\author{
Noriko Toyokawa ${ }^{1}$ (D) Nancy Darling ${ }^{2} \cdot$ Teru Toyokawa $^{3}$ \\ Accepted: 16 September 2021 / Published online: 11 October 2021 \\ (c) The Author(s), under exclusive licence to Springer Science+Business Media, LLC, part of Springer Nature 2021
}

\begin{abstract}
When older parents experience age-related functional limitations, adult children may begin to monitor and try to control their parents' behavior. This shift can lead to tension due to differences in values both generations share, with parents prioritizing autonomy and self-sufficiency and adult children prioritizing safety and convention. Although a great deal of research on the transition from adolescence to adulthood focuses on governance transfer and changing boundaries of autonomy, monitoring, and control, less is known about how this happens in later life. The current study used qualitative methodology to explore the dynamic balance of autonomy, safety, and care between older parents and adult children who provide assistance in their daily lives. It focused on which areas adult children were most likely to monitor and try to control and how they did so, how parents respond to those efforts, and the dynamics of information management. Sixteen adult children who had at least one living parent $\left(M_{\text {age }}=53, S D=6.1\right)$ discussed the challenges of managing two conflicting caregiving goals: respecting parents' autonomy and ensuring parents' moral well-being, health, and safety. Data were analyzed using directive content analysis. Although participants were concerned about the negative consequences of their parents' current behaviors and health conditions, they rarely impinged on their parents' autonomy until they were prompted by an authority figure or had clear evidence that their parents' health or safety were threatened. Parents often kept information about their activities and well-being from their children in order to protect their autonomy. Implications for balancing parents and adult children's goals of governance transfer are discussed.
\end{abstract}

Keywords Family support $\cdot$ Intergenerational relations $\cdot$ Caregiving $\cdot$ Older adults $\cdot$ Monitoring $\cdot$ Information management

Family caregiving shifts dynamically across the life course (Eifert et al., 2016). Children dependent on parents grow into autonomous adults. Older parents ask adult children for instrumental and emotional support, which can come to be essential for their well-being. If older parents experience increasing disability, adult children may step in to compensate for their parents' functional declines (Funk, 2010) or become responsible for decisions about their parents' health and safety (Cicirelli, 2006). Although generational shifts in caregiving are complex at both ends of the life course (Eifert

Noriko Toyokawa

toyokawan@sou.edu

1 Psychology, Southern Oregon University, 1250 Siskiyou Blvd, Ashland, OR 97520, USA

2 Psychology, Oberlin College and Conservatory, Oberlin, $\mathrm{OH}$, USA

3 Human Development, California State University San Marcos, San Marcos, CA, USA et al., 2016), late-life transitions can be particularly stressful for both parents and adult children because they involve loss, rather than growth. Changing family dynamics can create tension between parents and their adult children as well as between siblings and between spouses (e.g., Lee et al., 2020; Wang et al., 2020).

The current article focuses on older parents who rely on their adult children for help. Specifically, we interviewed adult children about their caregiving, monitoring, and attempts to influence and control their older parents' behavior. The paper extends work on family dynamics, monitoring, and information sharing during adolescents' transition to adulthood (Darling et al., 2009; Smetana et al., 2009; Young et al., 2008) to understanding family dynamics during older parents' transition to late adulthood. It works from a social cognitive domain theory perspective, using domainspecific legitimacy of authority (Smetana et al., 2005) to provide insight into the changing dynamics of personal 
autonomy, privacy, monitoring, and information sharing of older parents and their adult children.

\section{Tension and Support}

Vygotsky introduced the metaphor of scaffolding to describe the process through which helpers support learners' functioning, allowing them to do more with aid than they can do on their own. Sensitive scaffolding provides just enough support for learners to use and extend their current abilities. Vygotsky argued that new learning occurs within the zone of proximal development, a semi-autonomous level of functioning (Daniels, 2017). Scaffolding supports continued functioning and the learning of new skills by (a) simplifying tasks so that the person being supported can succeed, (b) encouraging problem-solving dialogue between helper and the person being supported, (c) supporting learning and practicing new skills, and (d) promoting self-talk and problem solving when the supported person acts independently (Nieto, 2007). Although scaffolding is most frequently used to describe learning and growth, it has also been used to describe family and community supports for people living with dementia (McCabe et al., 2018). Scaffolding in old age is most apparent when adult children step in to help their older parents, for example, take over filling pill boxes or shopping so the parent can continue to live independently. Scaffolding may also facilitate the development of new skills. Functional loss often requires learning new ways of doing things, as when giving up driving requires learning to negotiate public transit. When sensitive scaffolding is used to support individuals no longer able to perform tasks they had previously been able to, the person being helped is better able to maintain their abilities through use and learn new ways of reaching their goals.

Unfortunately, scaffolding is frequently mismatched, resulting in tension between older parents and adult children (Fingerman et al., 2011; Lee et al., 2020). One source of this tension is the difference in perspectives and priorities of older adults and their children. Although both older parents and adult children explicitly recognize the importance of parental autonomy and parents' right to control their own lives (Suitor et al., 2018), adult children place a relatively greater emphasis on protecting and safeguarding parents, emphasizing risk-avoidance over autonomy. Adult children providing aid may also find it easier to do something for their parents in the way they choose rather than to do it the way their parents prefer. A qualitative study of Black and White families showed cultural variability in generational tensions, with White adult children expressing more frustration with parents' attempts to maintain autonomy and function than Black adult children (Suitor et al., 2018). Differences in the relative importance adult children and older parents place on risk-avoidance, convenience, autonomy, and control can all contribute to tension, conflict, and misplaced helping.

Frustration, ineffective scaffolding, and misplaced helping also result from differences in parents' and adult children's perception of parent's competence, functioning, and needs (Huo et al., 2018). Children report that their parents have more problems and greater disabilities than their parents report themselves (Lee et al., 2020). Discrepancies may lead to unmet needs, unwanted help, or intrusion into parents' autonomy. The sources of these discrepancies are complex, including reports that adult children are hypervigilant about parental functioning because they fear being judged for not providing adequate care and reports that older parents may not accurately perceive problems due to functional decline. Perceptual bias works in both directions, with parents putting their 'best foot forward' with positive selfperception bias and worried adult children actively looking for signs of decline in parents and wanting to repay the care they received as children (Fingerman et al., 2011).

\section{Social Cognitive Domain Theory}

Generational shifts in autonomy and caregiving roles are not unique to old age. For the last two decades, governance transfer has been a major focus of research on the transition from adolescence to adulthood (e.g., Young et al., 2008). Parental monitoring of children's and adolescents' activities has long been studied as a protective factor and indicator of good parenting (e.g., Dornbusch et al., 1985). Stattin and Kerr (2000) reinterpreted the monitoring construct around information management and the co-construction of governance transfer. A key element of this work has been understanding how sharing information facilitates parental guidance and adolescents' ability to use their parents as helpers while maintaining autonomy, a form of scaffolding (e.g., Darling et al., 2006; Hawk et al., 2009). An important thread in this research is social domain theory and the concept of legitimacy of authority.

Legitimacy of authority refers to individuals' beliefs about the extent that others can regulate their behavior. A related concept, obligation to obey, refers to individuals' beliefs that one must abide by external regulation of one's behavior, whether or not one agrees. For example, most people in the United States believe it is reasonable for governments to regulate highway speed (i.e., it is a legitimate use of government authority). Most do not agree it is legitimate for governments to mandate contraceptive use (i.e., it is not a legitimate use of their authority). Within families, most adolescents in the United States agree that parents may legitimately regulate bedtimes, drinking, and physical aggression but it is not legitimate for parents to tell them they must listen to particular types of music or 
be friends with particular children (Darling et al., 2005). Adolescents believe they are obliged to obey parents' rules about some issues they think parents can regulate legitimately, like curfews, but not others, like drinking. Social domain theory posits that individuals believe that different areas of issues can be legitimately controlled by others, depending on the domain which they assume the issue should be part of (Campione-Barr et al., 2015). Specifically, issues within the Personal domain are those that solely affect the individual involved and are thus outside the legitimate sphere of outside influence. Matters of taste (e.g., music, clothing) fall within the Personal domain. Moral issues are those defined by higher authority (e.g., religion or ethics) and can be regulated by others. Harming others or stealing are exemplars of such issues. Matters of convention (Conventional domain) are often defined as legitimate subject to regulation to the extent that they minimize friction between people or serve another purpose. Dressing respectfully in a church or mosque and using titles to address others are examples of conventional issues. Prudential issues are issues related to health and safety. For example, speed limits protect the health of both the driver and others. In childhood, prudential issues are seen as legitimately regulated by parents in their role as caregivers. As children become adolescents and adults, issues within the prudential domain that solely affect the individual become subsumed into the Personal. Those that affect both the individual and others are normatively seen as legitimate subject to external regulation and may fall into the Moral domain.

Many issues combine multiple domains or are seen differently by different people. For example, arguments over the legitimacy of mask mandates during the COVID-19 pandemic can be seen as a conflict between people who differ in the domain to which they believe mask-wearing belongs. If one thinks of mask-wearing as solely protecting the wearer, then it is a prudential issue within the Personal domain and its regulation is outside of the legitimate domain of authority. The individual may choose to protect themselves or to take a risk of being exposed to COVID-19. On the other hand, if one thinks of mask-wearing as protecting others around you (e.g., of stopping spread through contact), then it falls within the Moral domain and can be legitimately regulated as protecting public safety. From this perspective, people defining mask-wearing as Personal will resent and perhaps resist the assertion of authority by the government to require masks because they do not consider it a legitimate domain of government authority. Those who define mask-wearing as Moral are more likely to comply, even if they disagree. Similarly, within families, parents and their young children often argue about issues such as clothing choices or cleaning bedrooms. Normatively, parents consider these issues to be Conventional, and thus a legitimate area of their authority, but children consider them to be Personal and not a legitimate area over which parents may assert control (Smetana, 1988).

There is a normative change in both parents' and children's beliefs about the domain classification of different issues as children become adolescents and then adults (e.g., Darling et al., 2008). In the United States, many health and safety issues that solely affect the individual (e.g., drinking, bedtime, using bicycle helmets) move into the Personal domain by late adolescence and are no longer seen as legitimate areas of parental control. There is a somewhat slower contraction of the number of issues adolescents believe they obligated to obey parents, and this varies more by culture. For example, a study of youth in the US, Chile, and Philippines showed that normative beliefs about children's obligation to obey parents in most domains extended into early adulthood, even though young adults did not believe it was appropriate for parents to assert this authority (Darling et al., 2005). By their mid-twenties, adult children are normatively considered to be autonomous decision-makers, and power assertion across generations considered outside the legitimate domain of parental authority.

Social domain theory has been particularly useful in thinking about intergenerational information management in the context of governance transfer. Research has documented that adolescents' decisions to share information with parents, to hide information or lie about issues, to obey parents, and to argue with them depends upon the quality of their relationship (e.g., how warm it is and the extent to which autonomy is respected and parents have high behavioral expectations), the extent to which adolescents agree with their parents, but also upon their beliefs about parents' legitimate authority over the issue in question (Darling et al., 2006; Nucci et al., 2014;Tilton-Weaver et al., 2014). There is suggestive evidence that these findings are also generalizable across other relationships. Adolescents and young adults report that they are less likely to adhere to medical advice from doctors when they believe the area in question is not legitimately within the domain of doctors' authority (Darling \& Mendicino, 2020). For example, youth are more likely to endorse ignoring doctors' advice and lying to doctors about stress reduction and meditation, which are in the Personal domain, than areas that are Multifaceted (e.g., diet). They report being obligated to obey and unlikely to lie in Prudential areas like medication that are more traditionally within the professional scope of medical expertise.

The social domain framework for thinking about generational dynamics has not been extended into late adulthood, when caregiving roles go through a generational shift. Qualitative research on the dynamics of caregiving in adult children and their older parents is suggestive, however. Suitor and his colleagues (2018) reported that adult children believe that parents are autonomous and that they 
do not have right to control their parents' behavior, even when it worries them. This is consistent with research from a social domain perspective that most issues not affecting others fall within the Personal domain and are thus not subject to external regulation. In a qualitative study of scaffolding in old age, parents with dementia talked about decisionmaking as collaborative, suggesting that they were granting their child some degree of legitimate authority over decisions (McCabe et al., 2018). It is interesting that the Prudential domain, including issues of health and safety (e.g., driving) and issues typically defined as Conventional (e.g., cleaning, how one dresses) are the earliest areas where adult children seem involved in decision-making. These are the last domains over which adolescents grant parents legitimate control. Social cognitive domain theory can be useful in thinking about individual, family, and cultural differences in caregiving. For example, Suitor and colleagues (2018) reported that adult children in White families expect more decision-making power over parents' life choices, whereas Black adult children seemed to rely more on persuasion. These differences may reflect differences in the extent to which issues are thought of as within the Personal domain, which cannot be legitimately controlled by others, or the Prudential or Conventional domains.

\section{Difference in Developmental Goals}

During governance transfer in later life, adult children often report that parents reject the child's care and protection in favor of autonomy, persisting in their own ways, opinions, and behaviors to achieve their own goals and pursuits (Heid et al., 2015). Developmental schisms theory (Fingerman, 1996) hypothesizes that these differences are due to differences in the developmental stages of parents and children. The developmental goals of parents whose functional ability is declining are the maintenance of autonomy and functional health without relying on their children's assistance (Utz et al., 2004). These goals appear to be normative among older adults across cultures and nations (Reich et al., 2020). Adult children also respect their parents' autonomy and right to make decisions without being influenced by others (Holstein et al., 2010). However, adult children prioritize maintaining parents' health and safety, see it as their obligation to ensure their parents' health and safety, and will interfere with parents' autonomy if they think it is necessary to do so (Zarit \& Egeebeen, 2005). This sets up a situation where older parents and adult children both value parent autonomy, health, and safety, but perceive different needs, have different priorities, and come into conflict because of their different developmental tasks.

As with generational conflict earlier in life, late-life conflicts can be conceptualized as generational conflicts in beliefs about the legitimate assertion of authority. Parents continue to think of most daily issues as within the Personal domain, affecting them and no one else. Adult children may come to see some areas of their parents' lives as Multidimensional, including elements of the Conventional or Prudential domains. Expressed concern that they will be judged as irresponsible or unloving children suggests adult children believe there is a normative expectation that they will care for parents' Prudential needs. Expectations by parents that they provide aid (e.g., requests to for transportation) moves an issue out of the Personal domain. For example, Sinclair et al. $(2019$, p. 593) quote a 67 -year-old man living with dementia talking about problems as jointly owned: “.... we are faced here with a problem that you and I have and you and I have to deal with it. So, it's not individual.... all those people are somehow affected." In this case, it appears the older parent (and presumably adult child) recognizes that the issue is no longer solely in the Personal domain because decisions made about the issue affect both of their lives.

Parents and adult children may not always share an understanding, however. A parent may believe that an issue is still Personal and that the child is simply providing a service that they are obligated to perform. Adult children may believe that because their parent is unable to make decisions they believe are appropriate, the domain has moved entirely into a Prudential area that the adult child is responsible for. Adolescents respond to parents' attempts to assert authority over areas they define as Personal by hiding information to maintain autonomy (Hawk et al., 2009). Differences in beliefs about the legitimacy of power authority are likely to lead to conflict and information management strategies that reduce conflict and assert autonomy, such as hiding information, partial concealment, or direct lying (Darling, et al., 2006).

\section{The Current Study}

The major goal of the current study is to explore the dynamic balance of autonomy, safety, and care between older parents and adult children who provide assistance in their daily lives. Specifically, we address five research questions:

1. In what issues and situations of parents' lives do adult children monitor parent behavior and interfere with their parents' autonomy?

2. How do adult children impinge on their parents' autonomy?

3. How do older parents respond to their children's attempts to monitor and regulate their behavior, particularly with regard to information sharing?

4. How do adult children perceive their parents' efforts to manage and withhold information the adult children believe they need to keep their parents safe? 
5. How do adult children respond to parents withholding management?

\section{Method}

\section{Participants}

Sixteen adult children participated in the present study $\left(M_{\text {age }}=53, S D=6.1\right)$. The study participants were selected based on the following criteria: adults who (1) had at least one living parent at the time when this study was conducted and (2) contacted their parents at least once a week. Among 16 participants, seven participants identified themselves as the primary caregivers of their living parents. All participants lived in the Greater San Diego area. Table 1 shows the demographic background of the study participants. To maintain the participants' anonymity, all names used in this report are pseudonyms.

\section{Procedure}

We conducted a focus group study on adult children's experiences providing home care, facilitated by the first author and assisted by six undergraduate research assistants. Undergraduate research assistants received $20 \mathrm{~h}$ of training on later-life parent-child relations, participant recruitment, data transcription, and field note taking prior to contacting possible participants. We followed the guidelines for qualitative studies in general outlined by Levitt et al. (2018) and focus group procedures (Krueger, 2014). To recruit participants for the present study, research assistants visited churches and volunteer groups with which they were affiliated in their local communities. Initially, three people agreed to participate in the study. Adopting a purposeful snowball sampling method (Palinkas et al., 2015), the research assistants asked those three individuals to introduce them to friends who also might be interested in participating in the present study. All participants used the selection criteria described above.

We held four 1-h focus groups, each with four participants. Focus groups were scheduled during weekends in summer 2017 at a conference room at a regional university, with participants scheduled to match their own preference. The groups each had different demographic backgrounds. For example, in one group all participants were Latina, whereas another group consisted of one Latino, one White male, one Latina, and one Black female participant. Table 1 shows participants' demographic characteristics and the focus group session in which each participant attended. Before each focus group started, participants were told they would be asked about their experiences with their living parents, then, asked to read and sign consent forms, and fill the demographic characteristic survey. The first author facilitated all focus groups. Semi-structured questions included 'In what situations do you usually intervene into your parents' issues?,' 'In what ways do you intervene into your parents' issues?,' 'How openly do you and your parents communicate about your parents' issues of life?,' 'What issue should you have known about but your parents did not tell you?,' and 'How do you manage situations if your parents do not tell you about critical issues of their lives?.' Prompts were given when needed. All focus group discussions were audio-recorded with participants' consents. Two research assistants in each session took field notes to record main ideas and record relevant observations. At the end of the focus group, each participant received a $\$ 20$ honorarium.

\section{Data Analysis}

The first author and six research assistants transcribed voice recordings of focus group interviews and copied notes on critical quotes on the transcription to confirm their accuracy (Krueger, 2014). The transcriptions were exchanged so the accuracy of each transcription was confirmed by at least one other person.

Two authors of the current study, both of whom had experience conducting qualitative studies, were engaged in data coding. Prior to data coding, the authors agreed to exclude a few instances where participants mentioned their experiences with deceased parents, which were not the focus of the current study. Participants' statements were the unit of analysis for coding purposes. The words recorded for field notes were used to confirm how participants' statements were connected to each question. We employed directed content analysis (Hsieh \& Shannon, 2005) to code data regarding the issues and situations where participants intervened into parents' autonomy. Each transcribed interview was first read several times to gain a deep understanding of the data. Next, important statements were highlighted to identify initial codes or meaning units in the interview text. In the next phase, similar meaning units (codes) were placed into categories from a priori coding schema. In the present study, we adopted a priori coding schema from a domainspecific theory which has widely been used in research on adolescent development (Smetana, 1989). Using the coding schema, participants' responses were coded into one of the five categories or domains (i.e., moral, prudential, conventional, personal, multifaceted). For example, in adolescent research, adolescents' behavior such as driving under the influence is coded as 'adolescent's behavior that violates a law determined by a higher authority and involves others' safety' and is categorized into the domain of 'Moral' (e.g., Smetana, 1999). In the current study, the text of one participant's response: 'My father may need to return his 


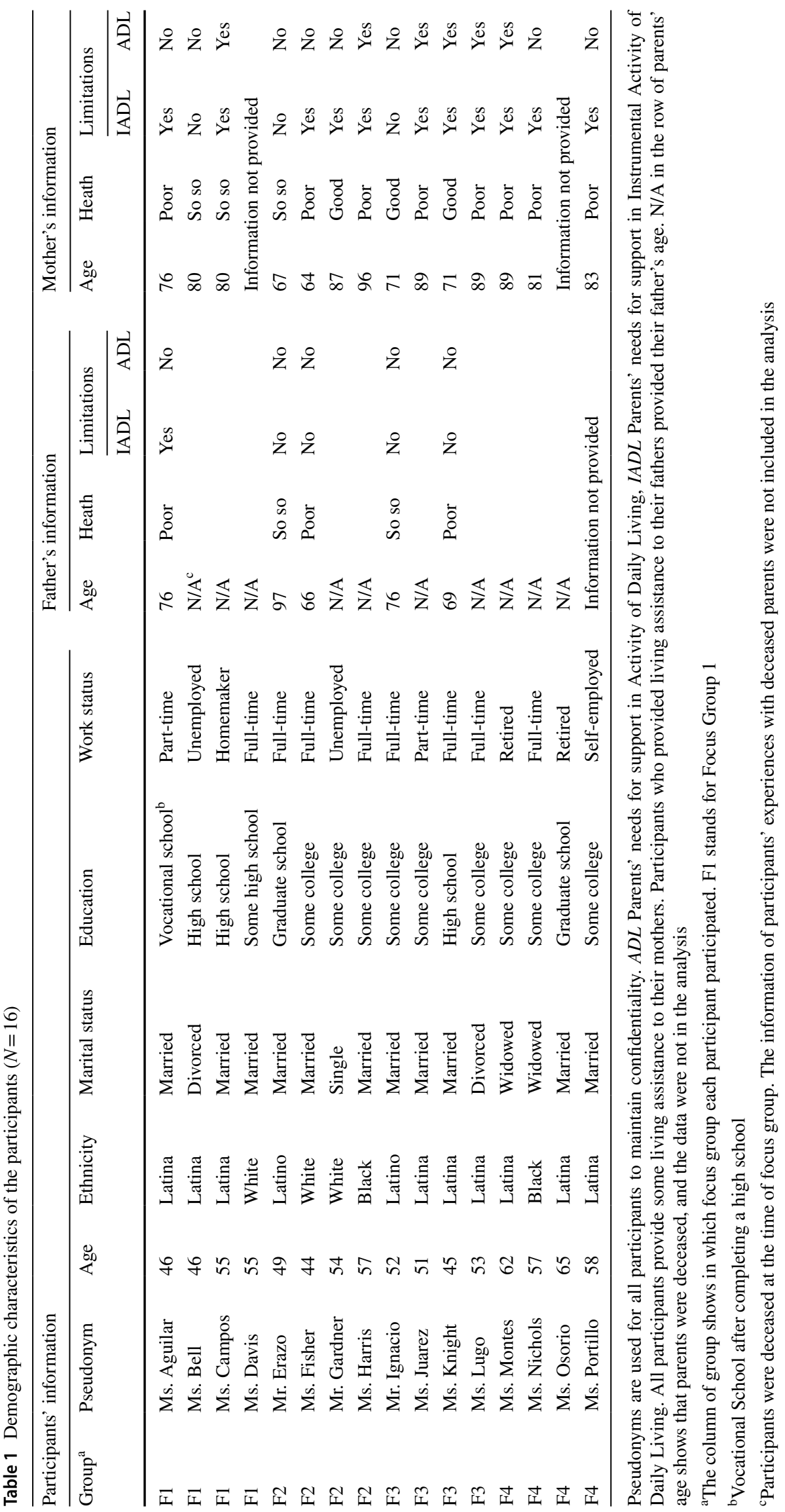


driver's license to prevent accidents. I don't want him to involve other people in an accident' was coded as a 'behavior involving others' safety' and therefore, categorized into the 'moral' domain.

After coding the domains of issues in which adult children intervened, responses were coded and grouped into categories created by the authors using a conventional content analysis approach, inductively developing categories of participants' intervention strategies based on the common terms and themes found in participants' statements (Hsieh \& Shannon, 2005). For example, participants' statements such as 'I taught my father how to use a cell phone' and 'I taught my father to speak with a gesture to control his voice' were grouped into and labeled as 'teaching a new skill.'

Based on the inclusive saturation model (Saunders et al., 2018), the authors compared the coding results of the first three focus groups with those of the fourth focus group to confirm data saturation and decided there was no need for further data collection.

\section{Findings}

\section{Overall Findings}

Participants experienced conflicts between their role as children who should respect their parents' autonomy and their role as caregivers who should protect their parents' health, safety, and moral well-being. To balance conflicts and respect parents' autonomy as much as possible, participants monitored parents' prudential and moral well-being for a long time before overriding their parents' autonomy. The following themes were obtained and will be summarized in the next sections: Issues in Older Parents' Lives to Which Adult Children Intervened, Adult Children's Perceptions of Parents' Withholding Information, and Adult Children's Strategies in Managing Parents' Information Withholding.

\section{Adult Children's Intervention Strategies}

\section{Issues in Older Parents' Lives to Which Adult Children Intervened}

When asked what issues and situations in their parents' lives they intervened into, the participants in each focus group began by stating that, in principle, decisions on all issues in their parents' lives were their parents' personal decisions. All participants agreed with each other, making similar statements. There was also general agreement that the caregivers did not want (a) to invade their parents' privacy (intrusion) by gaining information their parents did not disclose voluntarily or (b) to change their parents' living situation against their parents' will (control). At the same time, however, adult children felt responsible for monitoring how parents were doing and determining whether they should intervene into their parents' autonomy to help and/ or protect them. One participant's statement represents this general agreement among participants about the conflicting need to respect privacy and autonomy but protect health and well-being. Prudential concerns were brought up frequently to justify intruding on parent autonomy.

In my culture, children must respect their parents. When our parents get old, we want them to be safe and healthy. Although we respect our parents' privacy, we sometimes need to know how our parents are doing. For example, where they make a trip, with whom they go, and how they treat their health issues. We must make sure to help them without stepping on their toes (Mr. Eranzo, Latino).

\section{Adult Children's Intervention Strategies}

As described in Table 2, despite sometimes serious concerns about their parents, participants did not override parents' autonomy in the short term, prioritizing parent autonomy over prudential concerns. The health and functional statuses of parents described by participants differed. Three levels of involvement emerged from the analysis: monitoring and discussion, efforts to persuade the parent to change their behavior, and overriding parents' autonomy. With the monitoring and discussing strategy, participants saw no current issues with their parents' functioning (e.g., driving or managing money), but were concerned about future deficits. Ms. Agular's statement represents a persuasive strategy in a moral issue.

My father has low vision in his right eye. I don't want him to hurt himself and involve others in an accident. When he was in a good mood, I asked him if he thought about giving up driving. He said, 'I can still drive. If I give up driving, no one can give your mom rides to see doctors.' I do not see his driving as impaired now, but I keep checking how he drives (Ms. Angular, Latina).

Participants' efforts to respectfully persuade their parents to modify their current behaviors or to allow caregivers to provide aid or change their living environments were defined as persuasion strategies. Three types of persuasion strategies emerged in the analyses: (1) Discussing the consequences of the parents' current behavior, (2) Sharing a task with parents, and (3) Changing the environment to ensure 
Table 2 Types of participants' intervention into their older parents' autonomy and participants' belief in their parents' intentional or unintentional information withholding

\begin{tabular}{|c|c|c|c|c|}
\hline Issue & Parents' behaviors/conditions & Child's response & Type & Parents' information withholding ${ }^{\mathrm{a}}$ \\
\hline \multicolumn{5}{|l|}{ Moral } \\
\hline \multirow[t]{3}{*}{ Driving } & Drives with a health concern & Listens to parents' needs to drive & M & \\
\hline & $\begin{array}{l}\text { Drives with a serious health } \\
\text { concern }\end{array}$ & $\begin{array}{l}\text { Emphasizes risks involving others' } \\
\text { safety }\end{array}$ & MC & \\
\hline & Doctor says driving unsafe & Hides car keys & OR & \\
\hline Bad language use & Uses bad language to a minor child & Keeps the parent from children & OR & \\
\hline \multicolumn{5}{|l|}{ Prudential } \\
\hline \multirow[t]{4}{*}{ Living alone } & Insists on living alone & Respects parents' will & M & Parent is not aware of the seriousness \\
\hline & $\begin{array}{l}\text { Lives alone with a functional } \\
\text { limitation }\end{array}$ & Checks in frequently & STS & \\
\hline & Lives alone when frail & Renovates home for safety & SOE & \\
\hline & $\begin{array}{l}\text { Authority figure said living alone } \\
\text { unsafe }\end{array}$ & $\begin{array}{l}\text { Forces an alternative housing } \\
\text { arrangement }\end{array}$ & OR & \\
\hline \multirow[t]{4}{*}{ Medication } & Does not take medicine & $\begin{array}{l}\text { Explains the need for taking } \\
\text { medicine }\end{array}$ & $\mathrm{MC}$ & $\begin{array}{l}\text { Does not tell until asked or discov- } \\
\text { ered (3) }\end{array}$ \\
\hline & Does not follow prescriptions & $\begin{array}{l}\text { Creates a list of medicine for the } \\
\text { parent }\end{array}$ & SSR & \\
\hline & Overuses pain medications & Hides extra-medicine & OR & \\
\hline & Accidents due to a drug side effect & $\begin{array}{l}\text { Leads communication with parents' } \\
\text { doctors }\end{array}$ & OR & \\
\hline Medical treatment & $\begin{array}{l}\text { Seems to have a health problem } \\
\text { Insists no need for medical exams } \\
\text { Shows apparent symptoms }\end{array}$ & $\begin{array}{l}\text { Discusses the need to see a doctor } \\
\text { Convinces parents invoking the } \\
\text { name of God } \\
\text { Takes the parent to see a doctor }\end{array}$ & $\begin{array}{l}\mathrm{M} \\
\mathrm{MC} \\
\mathrm{OR}\end{array}$ & $\begin{array}{l}\text { Withholds information from the adult } \\
\text { child (4) }\end{array}$ \\
\hline Financial management & $\begin{array}{l}\text { Does not properly check bank } \\
\text { accounts } \\
\text { Provides unrealistic amount of } \\
\text { financial support to other adult } \\
\text { children } \\
\text { Lost property or savings }\end{array}$ & $\begin{array}{l}\text { Checks parents' account balance } \\
\text { Talks with parents and siblings } \\
\text { Obtains parents' power of attorney }\end{array}$ & OR & $\begin{array}{l}\text { Withholds information from the adult } \\
\text { child (4) }\end{array}$ \\
\hline Drinking & $\begin{array}{l}\text { Drinks heavily } \\
\text { Does not stop drinking heavily }\end{array}$ & $\begin{array}{l}\text { Starts talking about reducing con- } \\
\text { sumption } \\
\text { Hides alcohol bottles and cans }\end{array}$ & MC & \\
\hline \multirow[t]{2}{*}{ Death preparation } & $\begin{array}{l}\text { Has never talked about death } \\
\text { preparation }\end{array}$ & $\begin{array}{l}\text { Asks parents' plan for their end } \\
\text { of life }\end{array}$ & $\mathrm{MC}$ & $\begin{array}{l}\text { Order the adult child not to talk } \\
\text { about it (1) }\end{array}$ \\
\hline & $\begin{array}{l}\text { Uses parental authority to stop child } \\
\text { asking about the parent's death } \\
\text { preparation }\end{array}$ & Drops topic & GU & \\
\hline \multicolumn{5}{|l|}{ Conventional } \\
\hline Communication & Speaks loudly due to hearing loss & $\begin{array}{l}\text { Suggests alternative communica- } \\
\text { tion skills }\end{array}$ & STS & \\
\hline \multicolumn{5}{|l|}{ Multifaceted } \\
\hline Cleaning house & Does not clean house & $\begin{array}{l}\text { Cleans the house while parents are } \\
\text { out }\end{array}$ & PB & \\
\hline Smoking & Smokes heavily & Drops topic (Accepts the life style) & GU & \\
\hline \multirow[t]{2}{*}{ Contact } & $\begin{array}{l}\text { Does not regularly make contact } \\
\text { with participant }\end{array}$ & $\begin{array}{l}\text { Purchased a cell phone and taught } \\
\text { how to use }\end{array}$ & SSR & \\
\hline & Purposely lost a new cell phone & Goes to check on parent & GU & \\
\hline \multirow[t]{3}{*}{ Traveling } & $\begin{array}{l}\text { Travels without leaving am itiner- } \\
\text { ary }\end{array}$ & $\begin{array}{l}\text { Discusses a police officer's perspec- } \\
\text { tive }\end{array}$ & $\mathrm{MC}$ & \\
\hline & Travels with same-age peers & Invites parents to join family trips & SSR & \\
\hline & Parent is too frail & Stops parent from taking a trip & OR & \\
\hline Dating & Expresses interest in dating & $\begin{array}{l}\text { Helps parent to use online dating } \\
\text { sites }\end{array}$ & SSR & \\
\hline
\end{tabular}


Table 2 (continued)

\begin{tabular}{|c|c|c|c|c|}
\hline Issue & Parents' behaviors/conditions & Child's response & Type & Parents' information withholding ${ }^{a}$ \\
\hline & $\begin{array}{l}\text { Dates despite a chronic health } \\
\text { concern }\end{array}$ & $\begin{array}{l}\text { Checks in with the parent during } \\
\text { a date }\end{array}$ & SSR & \\
\hline & $\begin{array}{l}\text { Expresses interest in intercourse to } \\
\text { a doctor }\end{array}$ & $\begin{array}{l}\text { Drops topic (Embarrassment) } \\
\text { Accompany the parent to doctors' } \\
\text { appointment }\end{array}$ & GU & $\begin{array}{l}\text { Did not directly talk with the adult } \\
\text { child. Only talked with the family } \\
\text { doctor (1) }\end{array}$ \\
\hline
\end{tabular}

$M$ Monitor as implying the needs for parents' voluntary behavioral changes, $M C$ Monitor as convince their legitimacy of intervention, STS Support parents' autonomy by teaching skills, SSR Support parents' autonomy by sharing role, SOE Support parents' autonomy by optimizing the environment, $P B$ Perform parents' task behind parents' back, $O R$ Override parents' autonomy, $G U$ Give up influencing parents/Monitoring parents indirectly

${ }^{a}$ The number within the parenthesis shows the number of participants who mentioned about each experience

parents' safety or performing the task without the parents' knowledge.

My mother has friends of her age. She believes that she can make trips by herself, but I am concerned about trips only with older people. I told her, 'Mom, leave the information about where you will stay to me. If something happens to you, the police will ask me, 'Why don't you know where your mother is? You are her daughter!' (Ms. Fisher, White, discussing consequences).

My mother was involved in a car accident. I assume it occurred because she became drowsy because of the side effects of her medicine. Since the accident, I have had my mother show me all prescribed medications. I manage the information about my mother's medications by Excel (Ms. Fisher, White, sharing a task with parents).

My mother does not let me help her in the bathroom. I shout outside of the bathroom, 'Mom, can I help you? I am your daughter. You do not have to be shy! I want to make sure you do not fall.' She always says 'No! No one should get in!' So, I built handgrips, put no-slip sheets, and renovated the shower room and toilet (Ms. Osorio, Latina, changing the environment).

Participants overrode parents' autonomy in parents' moral and prudential issues when they convinced themselves that their parents were no longer capable of protecting their own health and safety. Overriding parental autonomy was relatively unusual and precipitated by an actual (not anticipated) problem in parents' moral or prudential issues or after receiving explicit instruction from an authority figure (e.g., a family minister, police officer, medical doctor) that they should intervene.

My Mom is insensitive to her language. When my son brought his friends to our home, Mom asked me loudly, 'Who is the fat boy?' I shouted to Mom, 'Don't call my son's friend fat! He must be hurt. My son will be hurt, too!' My Mom was like, 'So what?' Since then, I have never let my Mom stay in the same room with my son and friends. She would hurt children's hearts (Ms. Bell, Latina, the occurrence of a problem). My father's doctor said that he could not drive anymore. I hid his car key. He asks me, 'Where is my car key?' I just said, 'You can't drive anymore. There is no key!' and sold his car (Ms. Portillo, 58 years old, Latina, an authority figure's instruction).

Many issues are multifaceted, with the same activity categorized in different domains depending on context. Table 2 presents the analysis of domain membership. Ms. Davis's statement below is an example of how an issue (in this case, becoming romantically involved) has different facets. Ms. Davis responded to her mother's desire to date as a personal issue not subject to discussion or interference. Once her mother started to date, however, Ms. Davis monitored her mother's health and well-being in the context of dating because she had specific prudential concerns.

My Mom said that she wanted to date again after her 13 years as a widow. I sat down next to her and entered her information on a dating site. A few weeks later, she had a date. While she was dating, I checked in with her every hour. Mom has back pain. She can't sit in the same place in the same posture for a long time. I pretended to drive near her by chance, waving my hand from the other side of the road to say, 'Hi, Mom!' to make sure she was doing OK (Ms. Davis, White).

There were several cases where adult children interfered with parents' management of conventional issues that were not a threat to parents' health and safety. Examples include speaking with at an 'appropriate' volume or cleaning house before friends visited. Adult children accepted that their parents had well-established behavior patterns, and it would be challenging for the parents to change. Children suggested new skills, such as using gestures to prompt parents to talk 
more quietly or directly intervening by cleaning while a parent was at a daycare center rather than trying to persuade their parents to modify their behavior.

\section{Adult Children's Perceptions of Parents' Withholding Information}

The far-right column of Table 2 summarizes situations where parents did not share the information that their adult children felt they should know. Participants reported that parents avoided talking about their activities in three situations. First, adult children reported that parents withheld information when believed their children would disapprove of their activities.

My mom had lost her house. My younger sister and her husband convinced my mom to sell her house to purchase a spacious home to live with them. The plan did not work, and mom was left alone in a mobile house. She had excluded me from the plan with my sister. She did not want me to disturb her (Ms. Davis, White, disapproved activity).

The second situation occurred when parents and adult children disagreed about the seriousness of an issue or about declines in parents' functional ability. Thus, children felt they should have been informed about an issue the parent did not recognize as important. For example, Ms. Harris described how her mother believes that she could live alone in her house despite her functional limitations.

My mother had lived in her house alone in Alabama with a severe vision problem. Her living environment had a severe hygiene problem. Her minister called me to tell me that she could not live alone any longer. She still insisted on staying there because it 'is' her house. So, I tricked her. I invited her to visit me in California and had never let her return to Alabama. She must live with my family (Ms. Harris, Black, not aware of limitations).

Finally, participants believed that parents sometimes did not discuss information because of generational differences in what was appropriate to share.

When I asked my mother about her death preparation, where she wants to spend her last days of her life and what type of care she wants, she yelled at me, 'A daughter shouldn't ask such things to her mother!' She has never given me a chance to talk about it. I need to know about her plan, but she does not want to even think about her last days (Ms. Nicolas, Black, uncomfortable issue).
Ms. Nicolas's experience was followed up by focus group participants. Some participants interpreted parents' rejection of talking about particular issues as a typical response to the topic among their parents' generation.

Talking about death is a taboo issue for people of our parents' generation. They had been taught not to talk about these issues, even with their children openly. We should know about our parents' ideas of where they want to stay in their last days, what ceremony they want, and how they want to share their property with the offspring before our parents' health deteriorates. It will be too late if we attempt to ask about their plan for death preparation after their health status is critically deteriorated (Mr. Gardner, White, socialization in parents' generation).

In addition to the topic of death, a mother's unwillingness to talk to her daughter about her interest in having intercourse with her boyfriends was also attributed to generational differences that prohibited open communication about sex, even within a family. Participants did their best to interpret the reasons why their parents did not provide desired information to them and showed empathy towards parents who wanted to ensure their autonomy in these issues. Three participants who overrode their parents' autonomy in order to protect parents' financial health showed clear, strong emotions about having done so by shedding tears, sighing, and confessing that they had prayed to find a way not to hurt a parent who wanted to keep providing financial support for their youngest children at the parent's expense.

\section{Adult Children's Strategies in Managing Parents' Information Withholding}

When confronted with parents unwilling to provide the information they felt they needed, adult children redoubled their monitoring efforts. Rather than confronting parents directly, they regularly checked parents' bank accounts, monitored parents' phone calls, and counted medications. Adult children also monitored who their parents spent time with and accompanied their parents to doctors to ensure they had information about their health and their doctors' recommendations. By gathering information directly rather than asking their parents, they hoped to avoid conflicts and evade parental resistance. At the same time, adult children understood why parents withheld information and empathized with them. Ms. Davis' and Ms. Campos' statements are typical. Participants did not want to be intrusive or controlling but intervened into parents' autonomy with the intention to protect their parents from perceived risks to their health and safety. 
I was worried what she was taking a lot of hycodan because she is always having lots of pain. I was constantly questioning the amount she was taking and worried about if she was becoming an addict with her medication. She would get frustrated with me. She wouldn't tell me what she was taking. She didn't want to tell me anymore because she thought I would say something to the doctor about what she takes. So, I counted the number of hycodan in her medicine box to make sure she does not overdose on them (Ms. Davis, White).

When I took my mom's phone from her and directly told my sister that she should not call our mom for financial support anymore, my mom did not say anything. But I knew she was upset with me because when I made a cup of tea for her, I saw her arm was trembling because of anger. Because I am a mother of two children, I understand how my mom wants to help her youngest daughter, who needs money. My mom did not understand why I said No. I prayed to God and asked him how I could have done better. It was very hard. After that, I became my mom's power attorney (Ms. Campos, Latina).

Parents' intentional withholding of information about activities and plans and their unintentional withholding of information about their declining functional status limited participants' ability to monitor effectively. This lack of detailed information, combined with adult children's respect for their parents' autonomy, meant that participants rarely intervened until a problem needed immediate and substantial intervention. In most cases where participants reported their parents' withholding information about prudential health and safety issues, participants overrode parents' autonomy only after being prompted to do so by authority figure or after a serious problem had already occurred. Although participants intervened for the sake of parents' health and safety, participants did not feel comfortable overriding parents' autonomy.

\section{Discussion}

The current study used social domain theory (Smetana, 1999) to explore when and how adult children balanced two conflicting goals: respecting their older parents' autonomy and protecting their safety. Participants expressed strong feelings of responsibility for protecting their parents' health and safety (Prudential issues) and in protecting others from harm their parents might inflict (Moral issues). At the same time, they strove to respect their older parents' autonomy, recognizing the limits of their legitimate authority over the
Personal domain. Participants' distress when these goals came into conflict was salient.

Consistent with the recent study by Lee et al. (2020), reporting that adult children tended to perceive their older parents' functional limitations more seriously than their parents did, the current study's participants reported that their parents were not aware of their functional decline or the potential negative consequences of their behaviors. This perception gap between older parents and adult children is markedly similar to governance transfer in adolescence and early adulthood. During the transition to adulthood, parents focus on adolescents' safety and the long-term consequences of their behavior, setting rules in Prudential and Conventional areas. Although adolescents often recognize their parents' concerns as legitimate, they believe they can handle things on their own and assert their autonomy by ignoring parents, withholding information or lying to reduce conflict, disapproval, or interference (Darling et al., 2006; Smetana, 1999).

Although parents of adolescents are relaxing control and often feel relatively confident of the legitimacy of their authority, adult children of older parents are less sure of themselves. As concerns arise, most adult children begin with increased monitoring, gathering information to see if intervention is warranted (e.g., whether an issue has moved from the Personal to the Prudential or Moral). They then act to change parental behavior through persuasion, respecting parental autonomy over an issue that is still within the Personal domain. Only when prompted by immediate danger or when prompted by an outside authority do adult children intervene directly, and then with clear emotional distress. The dynamic of increasingly intrusive monitoring (checking bank accounts, following parents on dates) and parents' hiding information and lying in order to maintain autonomy is strikingly similar to the dynamic observed in adolescents. Adolescents are most likely to avoid issues, partially disclose information, or lie directly when believe their parents are impinging in areas where they do not have legitimate authority. Parents who believe their adolescents are hiding information often respond by increasing their intrusive monitoring (Hawk et al., 2009).

\section{Implications and Limitations}

Adult children's desire to both respect their parents' autonomy and to protect them from the negative consequences of functional decline comes out clearly in these interviews. It may be useful to reframe adult children's transition to caregiving roles as a joint project of older parents and adult children that clearly respects the boundaries of the Personal and Prudential, recognizing issues that have multifaceted components. The current study documented cases where 
adult children scaffolded their parents' learning new skills to help them maintain autonomy. $\mathrm{Wu}$ and her colleagues use the term growth for adaptation to refer to older adults' learning new information and skills to maintain functional independence (Wu et al., 2016). Such adaptations address both autonomy and prudential goals and could enhance the quality of the older parent-adult child relation. The conflict adult children experience when they feel pushed to intervene suggests many would be open to such an approach.

Several limitations of the current study are worth noting. First, the current study investigated governance transfer in later life only from an adult children's perspective. Because governance transfer is a joint project reflecting changing power dynamics in the older parent-adult child relationship, it is clear that the older parents' perspective needs to be heard. Second, because of the use of a snowball sampling method, sampling biases may have influenced the current study's findings. For example, this study oversampled women and Latinx participants. The issues and situations brought up by participants during focus groups are not exhaustive and may be culturally specific. Future research in governance transfer from an adult child's perspective needs to study a larger sample of older parent-adult child dyads from diverse racial and ethnic backgrounds to verify the current exploratory study's findings and examine contextual differences in adult children's challenges in the governance transfer processes.

\section{References}

Campione-Barr, N., Lindell, A. K., Giron, S. E., Killoren, S. E., \& Greer, K. B. (2015). Domain differentiated disclosure to mothers and siblings and associations with sibling relationship quality and youth emotional adjustment. Developmental Psychology, 51(9), 1278-1291. https://doi.org/10.1037/dev0000036

Cicirelli, V. G. (2006). Caregiving decision making by older mothers and adult children: Process and expected outcome. Psychology and Aging, 21(2), 209-221. https://doi.org/10.1037/0882-7974. 21.2.209

Daniels, H. (2017). Introduction to Vygotsky (3rd ed.). Routledge.

Darling, N., \& Mendicino, L. (2020, November 9). Following doctors' orders: Legitimacy of authority \& adolescent adherence [Video]. YouTube. https://www.youtube.com/watch?v=-PfYNdshD9U

Darling, N., Cumsille, P., Caldwell, L. L., \& Dowdy, B. (2006). Predictors of adolescents' disclosure to parents and perceived parental knowledge: Between- and within-person differences. Journal of Youth and Adolescence, 35(4), 667-678. https://doi.org/10.1007/ s10964-006-9058-1

Darling, N., Cumsille, P., \& Martinez, M. L. (2008). Individual differences in adolescents' beliefs about the legitimacy of parental authority and their own obligation to obey: A longitudinal investigation. Child Development, 79(4), 1103-1118. https://doi.org/ 10.1111/j.1467-8624.2008.01178.x

Darling, N., Cumsille, P., \& Peña-Alampay, L. (2005). Rules, legitimacy of parental authority, and obligation to obey in Chile, the Philippines, and the United States. New Directions for Child and
Adolescent Development, 108(Summer), 47-60. https://doi.org/ $10.1002 / \mathrm{cd} .127$

Darling, N., Cumsille, P., Peña-Alampay, L., \& Coatsworth, D. (2009). Individual and issue-specific differences in parental knowledge and adolescent disclosure in Chile, the Philippines, and the United States. Journal of Research on Adolescence, 19(4), 715-740. https://doi.org/10.1111/j.1532-7795.2009. 00608.x

Dornbusch, S. M., Carlsmith, J., Bushwall, S., Ritter, P., Leiderman, H., Hastorf, A., \& Gross, R. (1985). Single parents, extended households, and the control of adolescents. Child Development, 56, 326-341. https://doi.org/10.2307/1129723

Eifert, E. K., Adams, R., Morrison, S., Strack, R., \& A. . (2016). Emerging trends in family caregiving using the life course perspective: Preparing health educators for an aging society. American Journal of Health Education, 47(3), 176-197. https://doi.org/ 10.1080/19325037.2016.1158674

Fingerman, K. L. (1996). Sources of tension in the aging mother and adult daughter relationship. Psychology and Aging, 11(4), 591606. https://doi.org/10.1037/0882-7974.11.4.591

Fingerman, K. L., VanderDrift, L. E., Dotterer, A. M., Birditt, K. S., \& Zarit, S. H. (2011). Support to aging parents and grown children in black and white families. The Gerontologist, 51(4), 441-452. https://doi.org/10.1093/geront/gnq114

Funk, L. M. (2010). Prioritizing parental autonomy: Adult children's accounts of feeling responsible and supporting aging parents. Journal of Aging Studies, 24(2010), 57-64. https://doi.org/10. 1016/j.jaging.2008.03.003

Hawk, S. T., Keijsers, L., Hale, W. W., \& Meeus, W. (2009). Mind your own business! Longitudinal relations between perceived privacy invasion and adolescent-parent conflict. Journal of Family Psychology, 23(4), 511-520. https://doi.org/10.1037/a0015426

Heid, A. R., Zarit, S. H., \& Fingerman, K. L. (2015). "My parent is so stubborn!"-Perceptions of aging parents' persistence, insistence, and resistance. Journals of Gerontology Series b: Psychological Sciences and Social Sciences, 71, 602-612. https://doi.org/10. 1093/geronb/gbu177

Holstein, M. B., Waymack, M., \& Parks, J. A. (2010). Ethics, aging, and society: The critical turn. Springer publishing company.

Hsieh, H. F., \& Shannon, S. E. (2005). Three approaches to qualitative content analysis. Qualitative Health Research, 15(9), 1277-1288. https://doi.org/10.1177/1049732305276687

Huo, M., Graham, J. L., Kim, K., Zarit, S. H., \& Fingerman, K. L. (2018). Aging parents' disabilities and daily support exchanges with middle-aged children. The Gerontologist, 58(5), 872-882. https://doi.org/10.1093/geront/gnx144

Krueger, R. A. (2014). Focus groups: A practical guide for applied research. Sage publications.

Lee, H. J., Kim, K., Bangerter, L. R., Zarit, S. H., \& Fingerman, K. L. (2020). Aging parents' and middle-aged children's evaluations of parents' disability and life problems. Journal of Adult Development, 27(2), 135-146. https://doi.org/10.1007/ s10804-019-09336-x

Levitt, H. M., Bamberg, M., Creswell, J. W., Frost, D. M., Josselson, R., \& Suárez-Orozco, C. (2018). Journal article reporting standards for qualitative primary, qualitative meta-analytic, and mixed methods research in psychology: The APA Publications and Communications Board task force report. American Psychologist, 73(1), 26-46. https://doi.org/10.1037/amp0000151

McCabe, L., Robertson, J., \& Kelly, F. (2018). Scaffolding and working together: A qualitative exploration of strategies for everyday life with dementia. Age and Ageing, 47(2), 303-310. https://doi.org/ 10.1093/ageing/afx 186

Nieto, C. G. H. (2007). Applications of Vygotskyan concept of mediation in SLA. Colombian Applied Linguistics Journal, (9), 213228. https://doi.org/10.14483/22487085.3152 
Reich, A. J., Claunch, K. D., Verdeja, M. A., Dungan, M. T., Anderson, S., Clayton, C. K., Goates, M. C., \& Thacker, E. L. (2020). What does "successful aging" mean to you?: Systematic Review and cross-cultural comparison of lay perspectives of older adults in 13 countries, 2010-2020. Journal of Cross-Cultural Gerontology, 1-24(4), 455-478. https://doi.org/10.1007/s10823-020-09416-6

Saunders, B., Sim, J., Kingstone, T., Baker, S., Waterfield, J., Bartlam, B., Burroughs, H., \& Jinks, C. (2018). Saturation in qualitative research: Exploring its conceptualization and operationalization. Quality \& Quantity, 52(4), 1893-1907. https://doi.org/10.1007/ s11135-017-0574-8

Sinclair, C., Gersbach, K., Hogan, M., Blake, M., Bucks, R., Auret, K., Clayton, J., Stewart, C., Field, S., Radoslovich, H., Agar, M., Martini, A., Gresham, M., Williams, K., \& Kurrle, S. (2019). "A Real bucket of worms": Views of people living with dementia and family members on supported decision-making. Journal of Bioethical Inquiry, 16(4), 587-608. https://doi.org/10.1007/ s11673-019-09945-x

Smetana, J. G. (1989). Adolescents' and parents' reasoning about actual family conflict. Child Development. https://doi.org/10. 2307/1130779

Smetana, J. G. (1999). The role of parents in moral development: A social domain analysis. Journal of Moral Education, 28, 311-321. https://doi.org/10.1080/030572499.103106

Smetana, J., Crean, H. F., \& Campione-Barr, N. (2005). Adolescents' and parents changing conceptions of parental authority. New Directions for Child and Adolescent Development, 108(Summer), 31-46. https://doi.org/10.1111/j.1467-8624.2004.00749.x

Smetana, J. G., Villalobos, M., Tasopoulos-Chan, M., Gettman, D. C., \& Campione-Barr, N. (2009). Early and middle adolescents' disclosure to parents about activities in different domains. Journal of Adolescence, 32(3), 693-713. https://doi.org/10.1016/j.adole scence.2008.06.010

Stattin, H., \& Kerr, M. (2000). Parental monitoring: A reinterpretation. Child Development, 71(4), 1072-1085. https://doi.org/10.1111/ 1467-8624.00210

Suitor, J. J., Gilligan, M., Rurka, M., Con, G., Peng, S. Y., \& Pillemer, K. (2018). Conflict with mothers and siblings during caregiving:
Differential costs for Black and White adult Children. Journals of Gerontology Series B-Psychological Sciences and Social Sciences, 73(7), E86-E97. https://doi.org/10.1093/geronb/gbx149

Tilton-Weaver, L. C., Marshall, S. K., \& Darling, N. (2014). What's in a name? Distinguishing between routine disclosure and selfdisclosure. Journal of Research on Adolescence, 24(4), 551-563. https://doi.org/10.1111/jora.12090

Utz, R. L., Reidy, E. B., Carr, D., Nesse, R., \& Wortman, C. (2004). The daily consequences of widowhood: The role of gender and intergenerational transfers on subsequent housework performance. Journal of Family Issues, 25(5), 683-712. https://doi.org/10.1177/ 0192513 X03257717

Wang, H. W., Kim, K., Birditt, K. S., Zarit, S. H., \& Fingerman, K. L. (2020). Middle-aged children's coping strategies with tensions in the aging parent-child tie. International Journal of Aging \& Human Development, 90(3), 234-254. https://doi.org/10.1177/ 0091415018822079

Wu, R., Rebok, G. W., \& Lin, F. V. (2016). A novel theoretical life course framework for triggering cognitive development across the lifespan. Human Development, 59(6), 342-365. https://doi.org/ $10.1159 / 000458720$

Young, R. A., Marshall, S. K., Domene, J. F., Graham, M., Logan, C., Zaidman-Zait, A., Mart, A., \& Lee, C. M. (2008). Transition to adulthood as a parent-youth project: Governance transfer, career promotion, and relational processes. Journal of Counseling Psychology, 55(3), 297-307. https://doi.org/10.1037/0022-0167. 55.3.297

Zarit, S. H., \& Egeebeen, D. J. (2005). Parent-child relationships in adulthood and later years. In M. H. Bornstein (Ed.), Handbook of parenting: Children and parenting (2nd ed., pp. 135-161). Lawrence Erlbaum.

Publisher's Note Springer Nature remains neutral with regard to jurisdictional claims in published maps and institutional affiliations. 